Published in final edited form as:

J Am Chem Soc. 2016 April 6; 138(13): 4512-4521. doi:10.1021/jacs.5b13449.

\title{
A chemical controller of SNARE-driven membrane fusion that primes vesicles for $\mathrm{Ca}^{2+-t r i g g e r e d ~ m i l l i s e c o n d ~ e x o c y t o s i s ~}$
}

\author{
Paul Heo ${ }^{\dagger, \ddagger}$, Yoosoo Yang ${ }^{\dagger, \S, \ddagger}$, Kyu-Young Han ${ }^{\|, \perp}$, Byoungjae Kong $^{\dagger}$, Jong-Hyeok Shin ${ }^{\dagger}$, \\ Younghoon Jung ${ }^{\dagger}$, Cherlhyun Jeong ${ }^{\S}$, Jaeil Shin ${ }^{\nabla}$, Yeon-Kyun Shin ${ }^{\nabla}, T^{2}$ Taekjip Hall, ${ }^{\|, \bullet,}{ }^{*}$, \\ and Dae-Hyuk Kweon ${ }^{\dagger}{ }^{*}$ \\ tDepartment of Genetic Engineering, College of Biotechnology and Bioengineering, and Center \\ for Human Interface Nano Technology, Sungkyunkwan University, Suwon, Gyeonggi-do 440-746, \\ South Korea \\ §Biomedical Research Institute, Korea Institute of Science and Technology, Seoul 136-791, South \\ Korea \\ "Howard Hughes Medical Institute, Baltimore, MD 21205, United States \\ ${ }^{\perp}$ CREOL, The College of Optics \& Photonics, University of Central Florida, Orlando, Florida \\ 32816, United States \\ ${ }^{\nabla}$ Department of Biochemistry, Biophysics and Molecular Biology, lowa State University, Ames, IA \\ 50011, United States \\ Department of Biophysics and Biophysical Chemistry Johns Hopkins University School of \\ Medicine, Baltimore, MD 21205 United States \\ \Department of Biophysics, Johns Hopkins University, Baltimore, MD 21218 United States \\ -Department of Biomedical Engineering, Johns Hopkins University, Baltimore, MD 21205, United \\ States
}

\section{Abstract}

Membrane fusion is mediated by the SNARE complex which is formed through a zippering process. Here, we developed a chemical controller for the progress of membrane fusion. A hemifusion state was arrested by a polyphenol myricetin which binds to the SNARE complex. The arrest of membrane fusion was rescued by an enzyme laccase that removes myricetin from the

\footnotetext{
*Corresponding Author.dhkweon@skku.edu, tjha@jhu.edu.

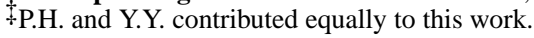

ASSOCIATED CONTENT

Supporting Information

The Supporting Information is available free of charge via the Internet at http://pubs.acs.org.

Supporting figures (Figure S1-S9)

Supporting table (Table S1)

Description of Movies (Movie S1,S2)

Supporting Materials and Methods

The authors declare no competing financial interest.
} 
SNARE complex. The rescued hemifusion state was metastable and long-lived with a decay constant of $39 \mathrm{~min}$. This membrane fusion controller was applied to delineate how $\mathrm{Ca}^{2+}$ stimulates fusion-pore formation in a millisecond timescale. We found, using a single-vesicle fusion assay, that such myricetin-primed vesicles with synaptotagmin 1 respond synchronously to physiological concentrations of $\mathrm{Ca}^{2+}$. When $10 \mu \mathrm{M} \mathrm{Ca}^{2+}$ was added to the hemifused vesicles, the majority of vesicles rapidly advanced to fusion pores with a time constant of $16.2 \mathrm{~ms}$. Thus, the results demonstrate that a minimal exocytotic membrane fusion machinery composed of SNAREs and synaptotagmin 1 is capable of driving membrane fusion in a millisecond time scale when a proper vesicle priming is established. The chemical controller of SNARE-driven membrane fusion should serve as a versatile tool for investigating the differential roles of various synaptic proteins in discrete fusion steps.

\section{Graphical abstract}

SNARE AR

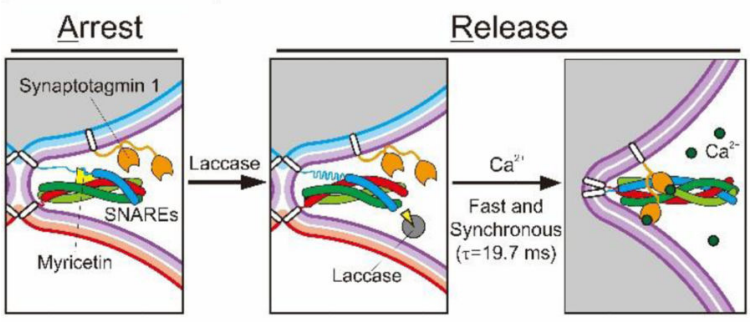

\section{INTRODUCTION}

Synaptic membrane fusion is mediated by soluble $N$-ethylmaleimide-sensitive factor (NSF) attachment protein receptor (SNARE) proteins. ${ }^{1-3}$ Neuronal SNAREs consist of vesicleassociated membrane protein 2 (VAMP2, Vp2) on the vesicle membrane and Syntaxin 1 (Stx) and SNAP-25 on the plasma membrane. ${ }^{4,5}$ These SNAREs drive membrane fusion by joining into a parallel four-helix bundle called SNARE complex. ${ }^{4,6}$ Overwhelming evidence favors the zippering hypothesis, in which SNARE complex formation starts from $\mathrm{N}$ terminals and zips progressively towards the membranes. ${ }^{7-11}$

$\mathrm{Ca}^{2+}$ triggers synaptic vesicle exocytosis, thereby releasing neurotransmitters contained in the vesicles, within one millisecond (ms) after arrival of the action potential. ${ }^{1-3,5,12,13}$ Although the key proteins regulating neuronal exocytosis have been identified, how $\mathrm{Ca}^{2+}$ influx brings about extraordinarily fast and synchronous neurotransmitter release remains controversial. To some extent, this is due to the fact that the molecular characteristics of primed vesicles and the structure of the trans SNARE complex in the readily releasable pool (RRP) are not known with certainty. In the most popular model, SNAREs are thought to be already partially zipped in the primed state. If this were the case, binding of $\mathrm{Ca}^{2+}$ to Synaptotagmin-1 (Syt1) would induce fusion by either disengaging from the partially zipped complex or removing complexin-1 from the complex. ${ }^{14-16}$ In some models that do not necessarily rely on the partially zipped complex, $\mathrm{Ca}^{2+}$-bound Syt1 triggers fusion by cooperating with SNAREs in bringing two membranes into close proximity or by directly remodeling the membranes. ${ }^{17-22}$ In the opposing scenario, it is envisaged that SNARE 
proteins are not connected in trans before $\mathrm{Ca}^{2+}$ influx, and instead SNARE proteins act as a single-shot device. ${ }^{3,8,17,23,24}$ Reconstitution of the primed state, which is ready to respond to $\mathrm{Ca}^{2+}$ influx through exocytosis in a millisecond timescale, is thought to help clarify the molecular mechanism underlying the remarkable speed and synchrony of neuroexocytosis. $1,8,9,22,25-28$ Until now, however, studies have not been successful in reconstituting the primed vesicles that exhibit every aspect of RRP in speed, synchrony, and reactivity to physiological $\mathrm{Ca}^{2+}$ concentrations.

Though the hemifusion state is a critical intermediate on the pathway to fusion pore opening, an experimental examination of this intermediate is impeded because there is no method available to efficiently prepare the hemifused vesicles. Previously, we have shown that a small molecule flavonoid myricetin binds near the ionic zeroth layer of SNARE complex during zippering, and results in a hemifused vesicle pair. ${ }^{29}$ This structural platform is expected to provide us with an opportunity to test hemifused vesicles as the substrate of various synaptic proteins if myricetin bound to SNARE complex can be removed. In the present study, we show that the arrested hemifused vesicle pairs become fusion-competent when myricetin is enzymatically lifted by laccase (EC 1.10.3.2). This experimental platform is then used to investigate how $\mathrm{Ca}^{2+}$ and the $\mathrm{Ca}^{2+}$-sensor protein Syt1 change fusion kinetics depending on the fusion stage. To assess the fusion stage-dependent effects of $\mathrm{Ca}^{2+}$ on fusion kinetics, we employed a single-vesicle fluorescence resonance energy transfer (FRET) lipid-mixing assay and a single vesicle-vesicle content-mixing assay, which have proven powerful in dissecting discrete fusion steps along the pathway of SNARE-driven membrane fusion..$^{9,22,26,30,31}$ Full lipid mixing and fusion pore opening were dramatically accelerated when $\mathrm{Ca}^{2+}$ was applied to the hemifused vesicle pairs. In contrast, $\mathrm{Ca}^{2+}$ asynchronously enhanced membrane fusion between docking vesicles. Based on these observations, a working model of the primed state is proposed.

\section{MATERIALS AND METHODS}

\section{Protein expression and purification}

Neuronal SNAREs from Rattus norvegicus: SNAP-25 (amino acids 1-206), full-length VAMP2 (Vp2, amino acids 1-116), soluble SNARE motif of VAMP2 (VpS, amino acids 196), and full-length Syntaxin 1a (Stx, amino acids 1-288) were expressed in Escherichia coli CodonPlus-RIL (DE3) and purified by a glutathione S-transferase (GST) tag system. In brief, cell pellets were resuspended in PBS (pH 7.4) supplemented with $2 \mathrm{mM} 4-(2-$ aminoethyl)-benzenesulfonyl fluoride, $2 \mathrm{mM}$ ethylenediaminetetraacetic acid (EDTA), and 2 $\mathrm{mM}$ dithiothreitol (DTT). After sonication, the supernatant was mixed with GST-agarose beads at $4{ }^{\circ} \mathrm{C}$ for $3 \mathrm{~h}$. Excess PBS was used for washing, and each protein of interest was eluted in thrombin cleavage buffer (TCB, $50 \mathrm{mM}$ Tris- $\mathrm{HCl}$ and $150 \mathrm{mM} \mathrm{NaCl}, \mathrm{pH} 8.0$ ). For transmembrane proteins, $0.2 \%$ Triton $\mathrm{X}-100$ and $0.05 \%$ Tween 20 were added to PBS for lysis and washing steps, and subsequently $1 \%$-octyl- $\beta$-D-glucopyranoside (OG) was added to TCB instead of Triton X-100 at the elution step. For full-length Synaptotagmin 1 (Syt1, amino acids 1-421), glycine at the 374 amino acid position was confirmed by DNA sequencing. Syt1 was expressed in E. coli Rosetta (DE3) pLysS (Novagen) and purified by a His-tag system. Specifically, to eliminate nucleic acid contamination, DNase and RNase 
were added to the buffer ( $50 \mathrm{mM}$ Tris- $\mathrm{HCl}, 300 \mathrm{mM} \mathrm{NaCl}, 20 \mathrm{mM}$ imidazole, $\mathrm{pH}$ 7.4) at the lysis step, and $20 \mathrm{mM} \mathrm{Ca}^{2+}$ was added to the buffer for several washing steps. Eluted Syt1 was dissolved in PBS with $1 \%$ OG and $500 \mathrm{mM}$ imidazole, and imidazole was removed by PD-10 desalting columns (GE Healthcare). All purified proteins were analyzed by SDSPAGE and Bradford assay.

\section{Reconstitution of T-, V-, and SV-vesicles}

Detailed reconstitution methods for ensemble lipid mixing assay, single-vesicle lipid mixing assay, and single-vesicle content mixing assay are described in the Supporting Information. T-acceptor complex composed of Stx and SNAP-25 were reconstituted in T-vesicle. Vvesicles contain Vp2 alone. SV-vesicles contain both Syt1 and Vp2.

\section{Ensemble lipid mixing assay}

T-, V-, or SV-vesicles were mixed together at a final concentration of $1 \mathrm{mM}$ lipids at a 9 (Tvesicle) to 1 (V- or SV-vesicle) molar ratio. The NBD signal was recorded at $465 \mathrm{~nm}$ and $530 \mathrm{~nm}$ for excitation and emission, respectively, with a Synergy H1 Hybrid Reader (BioTek Instruments). $\mathrm{Ca}^{2+}$ was injected into the mixture with a dispenser incorporated into the machine. To arrest membrane fusion at the hemifusion step, $5 \mu \mathrm{M}$ myricetin (Myr; Sigma Aldrich) was added to $\mathrm{T}$ - and $\mathrm{V}$-vesicle mixtures before the fusion reaction. To complete membrane fusion from hemifusion to full fusion, $10 \mathrm{U}$ laccase (Lac from Trametes versicolor, EC 1.10.3.2) was added to the mixture. At the end of the reaction, Triton X-100 was added to a final concentration of $0.1 \%(\mathrm{v} / \mathrm{v})$ to achieve the maximum NBD intensity. The lipid mixing percentage was calculated by converting the NBD fluorescence into percentage of maximum NBD fluorescence. The inner leaflet mixing assay was performed to estimate the hemifusion percentage. ${ }^{1,32}$ The hemifusion percentage was calculated as a function of time using the following equation: $2\left(\mathrm{P}_{\mathrm{T}}-\mathrm{P}_{\mathrm{I}}\right) /\left[\left(2\left(\mathrm{P}_{\mathrm{T}}-\mathrm{P}_{\mathrm{I}}\right)+\mathrm{P}_{\mathrm{I}}\right)\right] \times 100$, where $\mathrm{P}_{\mathrm{T}}$ is total lipid mixing $\%$ and $\mathrm{P}_{\mathrm{I}}$ is inner lipid mixing \% calculated from $\mathrm{V}$ - and T-vesicle fusion after treatment with $2.5 \mathrm{mM}$ sodium dithionite. ${ }^{33}$

\section{UV absorbance measurement}

The UV absorption spectra of polyphenols were measured at a concentration of $20 \mu \mathrm{M}$ in buffer solution (50 mM Tris- $\mathrm{HCl}, 150 \mathrm{mM} \mathrm{NaCl}, 2.5 \mathrm{mM} \mathrm{CaCl}_{2}, \mathrm{pH}$ 8.0) with SpectraMax M2 spectrophotometer (Molecular Devices Inc., USA). After preparing soluble SNARE motifs of the SNARE proteins, absorption spectra of the polyphenols were measured in the presence or absence of SNARE proteins. The absorbance spectra of SNARE complexpolyphenol mixtures were measured from 250 to $700 \mathrm{~nm}$ at a [polyphenol]/[SNARE complex] of $0.8 .^{34}$

\section{Single-vesicle lipid mixing assay}

A solution of $50 \mu \mathrm{g} / \mathrm{ml}$ neutravidin (Thermo Scientific) in T50 buffer (10 mM Tris- $\mathrm{HCl}$ and $50 \mathrm{mM} \mathrm{NaCl}, \mathrm{pH}$ 8.0) was introduced into the flow chamber, incubated for $10 \mathrm{~min}$, and then free neutravidin was washed out from the flow channel. For experimental scheme A, T- and $\mathrm{V}$ - or SV-vesicles (1.5 $\mu \mathrm{M}$ lipids/each vesicle) were incubated with $100 \mathrm{nM}$ myricetin at $37^{\circ} \mathrm{C}$ for $40 \mathrm{~min}$ in a 0.5 -mL Eppendorf tube. Hemifused vesicles were immobilized on the 
surface of a flow channel via biotin-neutravidin interaction. Unbound vesicles were washed out. The average number of immobilized vesicles was $341 \pm 53$ per single channel $(256 \times$ 512 pixels). To remove the myricetin from the SNARE zipper $0.01 \mathrm{U}$ preheated laccase was injected, incubated for $10 \mathrm{~min}$, and washed out. To observe Syt1-Ca ${ }^{2+}$ function at this stage, preheated $10 \mu \mathrm{M} \mathrm{Ca}^{2+}$ was injected into the channel. For scheme B, SV-vesicles with biotinDPPE were incubated in the channel for $10 \mathrm{~min}$ for immobilization onto the surface. Unbound vesicles were washed using excess dialysis buffer. The mixture of T-vesicles and designated concentrations of $\mathrm{Ca}^{2+}$ pre-incubated at $37{ }^{\circ} \mathrm{C}$ was then injected into the chamber. To prevent photobleaching of fluorescent dyes, we used imaging buffer consisted of $0.8 \%$ (w/v) D-glucose, $1 \mathrm{mg} / \mathrm{ml}(165 \mathrm{U} / \mathrm{ml}$ ) glucose oxidase (from Aspergillus niger [Type VII]; Sigma-Aldrich), $0.04 \mathrm{mg} / \mathrm{ml}$ (2170 U/ml) catalase (from bovine liver; Roche Applied Science), and 0.1\% (w/v) Trolox ( \pm -6-hydroxy-2,5,7,8-tetramethylchromane-2carboxylic acid; Sigma-Aldrich) dissolved in the dialysis buffer for observation. Every injection was performed by a custom-built injection system composed of a connector for drilling holes on glass, syringe connector, and Wall Excelon Mini-Bore Tubing ( $0.51 \mathrm{~mm}$ ID $\times 1.52 \mathrm{~mm}$ OD $\times 0.51 \mathrm{~mm}$, United States Plastic Corp.).

\section{Single-vesicle content mixing assay}

Every procedure was performed in exactly the same manner as that of the single-vesicle lipid mixing assay described above, except that SRB was contained in the SV-vesicles. Specifically, to enhance time resolution, we shortened the kinetic cycle of EMCCD to 10.14 $\mathrm{ms}$ (exposure time was $8.34 \mathrm{~ms}$ and lag time between each image was $1.8 \mathrm{~ms}$ ) and the imaging area was reduced to $128 \times 128$ pixels to detect superfast fusion pore opening.

\section{Data analysis}

Single-vesicle spots were identified by an IDL script (Research Systems Inc.), and their time traces were processed further using MATLAB (Mathworks). ${ }^{35}$ The FRET efficiency $(E)$ for the lipid mixing assay was calculated using the following equation: $E=\left(I_{a}-0.13 \times I_{d}\right) /\left(I_{a}+\right.$ $\left.I_{d}\right)$, where $I_{d}$ and $I_{a}$ are donor and acceptor fluorescence intensity, respectively, and 0.13 is the leakage factor. To better guide the low signal-to-noise ratio of the real-time single-vesicle content mixing traces, we used a nonlinear filter (CK filter) developed by Chuang and Kennedy to detect steep changes in fluorescence. ${ }^{36,37}$ The fitting curves were then used to calculate the relative fluorescence distribution histogram. To obtain the relative fluorescence distribution histogram before and after $\mathrm{Ca}^{2+}$ injection, the real-time fusion trace was treated as follows. A single fluorescence intensity trace was normalized between 0 and 1 using the minimal fluorescence intensity as 0 and the maximal fluorescence intensity as 1 in the time window of $-1-1 \mathrm{~s}$. As $\mathrm{Ca}^{2+}$ was injected at time 0 , the average of fluorescence intensity trace between $-1 \mathrm{~s}$ and $0 \mathrm{~s}$ and $0 \mathrm{~s}$ and $1 \mathrm{~s}$ were used to stand for the value of normalized fluorescence intensity for a trace before and after $\mathrm{Ca}^{2+}$ injection, respectively. The fluorescence intensity fitted using CK filter was also treated in the same way as above. Analysis of all 112 real-time traces clearly showed that the fluorescence intensity of all vesicles jumps up immediately upon $\mathrm{Ca}^{2+}$ injection. 


\section{RESULTS}

\section{Myricetin-mediated arrest-and-release control of membrane fusion}

We previously showed that myricetin, a natural small molecule polyphenol, brings about the arrest of membrane fusion at the hemifusion state by binding to SNARE complex. ${ }^{29,38}$ Here, we hypothesized that the myricetin-mediated hemifused state could provide us an opportunity to test hemifused vesicles as the substrate of various synaptic proteins if myricetin can be removed from the SNARE complex. After reconstitution of T-vesicle (containing Syntaxin 1 and SNAP-25) and V-vesicle (containing VAMP2) conventional lipid-mixing assays were performed to test this possibility. ${ }^{1}$ Bulk lipid mixing assays confirmed that myricetin inhibited inner leaflet mixing (Fig. 1A) leading to arrest in the hemifusion state (Fig. 1B). Then, myricetin was removed from the SNARE zipper by laccase (EC 1.10.3.2), a polyphenol-degrading enzyme. When laccase was added to the arrested state membrane fusion resumed, proceeding from the hemifusion state to full lipid mixing (Fig. 1B) as observed through inner leaflet mixing (Fig. 1A). To monitor whether myricetin was indeed removed from the SNARE complex upon laccase treatment, the bathochromic shift of myricetin was measured. ${ }^{39}$ Absorption maximum $\left(\lambda_{\max }\right)$ of myricetin shifted from 318 to $377 \mathrm{~nm}$ when free myricetin was bound to the SNARE complex (Fig. 1C). Laccase treatment moved $\lambda_{\max }$ to $333 \mathrm{~nm}$, which corresponds exactly to the oxidation product of free myricetin in solution. ${ }^{39}$ (Fig. S1A and B). Myricetin pre-oxidized by laccase before mixing with T- and V-vesicles did not inhibit SNARE-driven membrane fusion (Fig. S1C). These results suggested that myricetin was removed from the SNARE complex by laccase. The clamping activity of myricetin was not simply dependent on a single SNARE protein but was dependent on all 3 complex-comprising proteins (Fig. S2). Therefore, myricetin serves as the chemical switch of neuronal SNARE complex that provides a method to control SNARE-driven membrane fusion.

Myricetin-mediated arrest and release of SNARE-mediated membrane fusion (termed as SNARE AR) provided us with opportunities to use hemifused vesicles as the substrate of various synaptic proteins and to examine subsequent stages separate from early steps of membrane fusion such as docking. To this end, SNARE AR was applied to dissect membrane fusion at the single-vesicle level. T- and V-vesicles labeled with lipid dyes DiD (acceptor) and DiI (donor), respectively, were allowed to react in a tube for 0-60 min and then the vesicles were immobilized to the imaging surface through biotinylated lipids. The docked vesicles (FRET efficiency centered at $\sim 0.25)^{30}$ proceeded to full lipid mixing (FRET efficiency centered at $\sim 0.7)^{30}$ in a time-dependent manner (Fig. 1D). In contrast, reactions performed in the presence of $100 \mathrm{nM}$ myricetin showed enrichment of hemifused vesicles (FRET efficiency centered at $\sim 0.5$, Fig. 1E), consistent with the ensemble results (Fig. 1B). The fraction of vesicles arrested in the hemifusion state was dependent on myricetin concentration, reaching a saturation at about $100 \mathrm{nM}$ (Fig. S3A). We confirmed that at submicromolar concentrations, myricetin has no effect on vesicle size (Fig. S3B and C), efficiency of vesicle immobilization (Fig. S3D and E), or fluorescence intensity of liposomes (Fig. S3 E and F). When laccase was injected into the sample chamber at this stage, the hemifused population shifted towards full lipid mixing with time (Fig. 1F). Addition of 10 $\mu \mathrm{M} \mathrm{Ca}^{2+}$ alone without Syt1 did not affect these fusion processes. A recent study raised a 
caution about the use of lipid mixing as a reporter of membrane fusion because an asymmetry in fluorescence dequenching during fusion was observed depending on which vesicle ( $\mathrm{T}$ or $\mathrm{V}$ ) had a dye vs. a quencher. ${ }^{40}$ This does not appear to be the case for DiI and DiD used here because swapping the dyes labeling T- and V-vesicles gave similarly enriched hemifusion population in the presence of $100 \mathrm{nM}$ myricetin (Fig. S3G and H).

\section{Dissection of fusion-step specific effect of $\mathrm{Ca}^{2+}$ on full lipid mixing}

We included Syt1 in V-vesicles (SV-vesicle) to test whether SNARE AR could be applied to delineate the $\mathrm{Ca}^{2+}$-triggering stage of membrane fusion. Myricetin not only inhibited the fusion of SV-vesicles (Fig. 2A, red line), but also hindered the acceleration of fusion by $\mathrm{Ca}^{2+}$ in a bulk system (Fig. 2A, yellow line). Addition of $\mathrm{Ca}^{2+}$ into the reaction mixture ( $\mathrm{T}$ $+\mathrm{SV}$ ) did not induce full fusion when myricetin was not removed from the SNARE complex (Fig. 2A, yellow line). $\mathrm{Ca}^{2+}$ accelerated the fusion of $\mathrm{SV}$-vesicles only when myricetin bound to the SNARE complex was removed by laccase before $\mathrm{Ca}^{2+}$ injection (Fig. 2A, cyan line). Furthermore, when vesicles were prepared through SNARE AR on the imaging surface (Fig. 2B, scheme A), the hemifusion state remained stable even after myricetin removal, with a decay time constant of 39 minutes in the absence of $\mathrm{Ca}^{2+}$ (Fig. 2C), allowing us to examine the $\mathrm{Ca}^{2+}$-dependent fusion acceleration. Consistently with ensemble assays (Fig. 1A and 2A), Syt1 did not Preparing single vesicle pairs through SNARE AR (scheme A, Fig. 2B) yielded three populations of docked (22.6 $\pm 3.1 \%$, mean \pm standard deviation from 3 independent experiments), hemifused (62.5 $\pm 8.6 \%)$, and fully fused (14.9 $\pm 1.7 \%$ ) vesicles prior to $\mathrm{Ca}^{2+}$ addition. The fraction of vesicle populations did not change without $\mathrm{Ca}^{2+}$ addition or without laccase pre-treatment (Fig. 2D). Most vesicles arranged through SNARE AR simultaneously underwent full lipid mixing upon addition of $10 \mu \mathrm{M}$ $\mathrm{Ca}^{2+}$ (Fig. 2E, 2F, Fig. S4 and Movie 1). Because this happened within $32 \mathrm{~ms}$ of $\mathrm{Ca}^{2+}$ addition, which was the frame time of data acquisition, full lipid mixing of the vesicles perhaps occurred much earlier than $32 \mathrm{~ms}$ after $\mathrm{Ca}^{2+}$ arrival.

The binding of $\mathrm{Ca}^{2+}$ to Syt1 is known to alter the mode of interaction with both membrane and SNARE proteins, ${ }^{41}$ and participates in various stages of membrane fusion. ${ }^{3,17,25,42}$ Because SNARE AR enabled us to arrange hemifused vesicle pairs, which is otherwise observed transiently, we could investigate the fusion step-specific effect of $\mathrm{Ca}^{2+}$ by adding $\mathrm{Ca}^{2+}$ at different stages of fusion reaction (Fig. 2B). Adding T-vesicles premixed with $\mathrm{Ca}^{2+}$ to the imaging chamber with immobilized SV-vesicles (Fig. 2B, scheme B) may test whether $\mathrm{Ca}^{2+}$ accelerates full lipid mixing by catalyzing early stages of membrane fusion such as docking. ${ }^{22}$ This indeed yielded results consistent with those of a previous report ${ }^{22}$ in that (1) full lipid mixing events were dramatically increased by a physiological concentration of $\mathrm{Ca}^{2+}$ (Fig. 2F, gray triangles), (2) real-time traces of individual single-vesicle lipid mixing events exhibited multiple lipid mixing pathways (Fig. S5), and (3) higher concentrations of $\mathrm{Ca}^{2+}$ inactivated Syt1 (Fig. 2G). However, scheme A and scheme B yielded very different patterns of fusion acceleration by $\mathrm{Ca}^{2+}$. Acceleration in the number of full lipid mixing events by $\mathrm{Ca}^{2+}$ was several orders of magnitude greater in scheme A than in scheme B (Fig. 2F). The full fusion kinetics in scheme $A$ was well fitted to a single-exponential function with a time constant of $19.7 \mathrm{~ms}$ (Table S1), indicative of a single straightforward process to full fusion (Fig. 2F, red circles). In scheme B, both a slow and a fast kinetic component of 
lipid mixing were observed (Table S1), indicative of two distinct lipid-mixing acceleration processes by $\mathrm{Ca}^{2+}$-bound Syt1. The time constant of the fast component was $3.84 \mathrm{~s}$, which was $\sim 1 / 200$ slower full lipid mixing compared to scheme A. Inactivation of Syt1 at higher $\mathrm{Ca}^{2+}$ concentrations was not observed when $\mathrm{Ca}^{2+}$ was added to the hemifused vesicles (Fig. $2 \mathrm{G}) .^{22}$

After further analyzing all real-time lipid mixing traces (Fig. S6), we found that scheme A yielded the superfast full lipid mixing upon $\mathrm{Ca}^{2+}$ injection by primarily starting from the hemifusion state (Fig. 3A). When real-time FRET traces of individual vesicles were overlapped, scheme A yielded highly synchronized lipid mixing (Fig. 3B) while scheme B yielded signals of full fusion scattered throughout tens of seconds (Fig. 3C). These two contrasting patterns of full fusion are reminiscent of event histograms of asynchronous and synchronous neurotransmitter release, respectively. ${ }^{43}$ Even when real time FRET traces of scheme B were aligned by the emergence of docking signals (Fig. 3D and E), not by the addition of $\mathrm{Ca}^{2+}$ (Fig. 3C), the time gaps $\left(\Delta \mathrm{T}_{1}\right)$ between docking and full fusion were still irregular and poorly synchronized (Fig. 3E). When the distribution of $\Delta \mathrm{T}_{1}$ was fitted using exponential decays (Fig. 3G), the kinetic components were almost the same as in a previous study, ${ }^{22}$ with a time constant of the fast-kinetic component $402 \mathrm{~ms}$ (Table S1). This dockingto-full fusion transition of scheme B is 20 times slower than hemifusion-to-full fusion transition ( $\tau=19.7 \mathrm{~ms}$ ) in scheme A. When real time FRET traces of scheme B were aligned by the emergence of hemifusion signals (Fig. 3D and F), the time gaps $\left(\Delta \mathrm{T}_{2}\right)$ between hemifusion and full fusion were still poorly synchronous (Fig. 3E) with a decay constant of $141 \mathrm{~ms}$. This slow hemifusion-to-full fusion transition of scheme B compared with scheme A occurred perhaps because hemifusion intermediates were formed after $\mathrm{Ca}^{2+}$ influx. It is possible that the number of active Syt1 available for inducing $\mathrm{Ca}^{2+}$-triggered hemifusion-tofull fusion transition was reduced because Syt1 already interacted with its partners such as SNARE and membranes. This result suggests that Syt 1 and $\mathrm{Ca}^{2+}$ trigger synchronous full fusion only when they act on hemifusion intermediates while they enhance docking-to-full fusion transition relatively slowly and asynchronously.

\section{Reconstitution of $\mathrm{Ca}^{2+-t r i g g e r e d ~ m i l l i s e c o n d ~ n e u r o e x o c y t o s i s ~}$}

Next, we examined content mixing 9,31 following scheme A. To enhance time resolution, we shortened the recording frame time to $10 \mathrm{~ms}$ by reducing the field of view to $128 \times 128$ pixels. Sulforhodamine B (SRB) was encapsulated at self-quenching concentrations (50 $\mathrm{mM}$ ) in SV-vesicles and then incubated with unlabeled T-vesicles in the presence of myricetin to obtain hemifused vesicle pairs. The vesicle pairs were immobilized and treated with laccase to make the vesicles fusion-competent. The fluorescence intensity of vesicle pairs was stably maintained in the absence of $\mathrm{Ca}^{2+}$ (Fig. 4A), indicating that the hemifused vesicle pairs arranged through SNARE AR allowed neither leakage through bilayers nor $\mathrm{Ca}^{2+}$-independent spontaneous content-mixing between vesicles. About $31 \%$ of all SRBcontaining vesicles opened fusion pores in the presence of $10 \mu \mathrm{M} \mathrm{Ca}^{2+}$ when recorded for 10 $\mathrm{s}$. The fluorescence intensity changes observed after $\mathrm{Ca}^{2+}$ injection showed that vesicle pairs with fusion pores were clearly distinguishable from those without pores opened (Fig. 3B and C). 
We also prepared vesicles following the well-established method of single-vesicle content mixing assay to compare with scheme $\mathrm{A}$ in terms of kinetics of pore-opening. ${ }^{9,31,44,45} \mathrm{SV}$ vesicles containing SRB were added to the sample chamber and incubated with T-vesicles immobilized on a cover glass at $25^{\circ} \mathrm{C}$ for $1 \mathrm{~min}$. After free $\mathrm{SV}$-vesicles were washed out, the interacting vesicle pairs were further incubated at $25^{\circ} \mathrm{C}$ for $40 \mathrm{~min}$ (Fig. S7, scheme C). After $\mathrm{Ca}^{2+}$ injection at different concentrations, content-mixing events were monitored by observing changes in fluorescence intensity for $10 \mathrm{~s}$. It is thought that the incubation at zero $\mathrm{Ca}^{2+}$ concentration establishes docked vesicle pairs, $, 9,31$ though the initial state of the individual vesicle pairs at the time of $\mathrm{Ca}^{2+}$ injection is still uncertain. ${ }^{44,45}$ When $500 \mu \mathrm{M}$ $\mathrm{Ca}^{2+}$ was injected $14 \%$ of the SRB-containing vesicles opened fusion pore in $10 \mathrm{~s}$. When the cumulative content mixing event was fitted to a double-exponential first-order kinetics time constants for fast and slow component were $474 \mathrm{~ms}$ and $2.55 \mathrm{~s}$, respectively, which are comparable values to those of a previous report (Table S1). ${ }^{9}$ Consistent with previous studies, $, 931,44,4510 \mu \mathrm{M} \mathrm{Ca}^{2+}$ did not trigger content mixing of the vesicle pairs arranged through scheme C (Fig. 4D). In contrast, the hemifused vesicle pairs arranged through SNARE AR (scheme A) immediately opened fusion pores upon addition of $10 \mu \mathrm{M} \mathrm{Ca}^{2+}$, with a time constants of fast and slow components of $16.2 \mathrm{~ms}$ and $916 \mathrm{~ms}$, respectively (Fig. 4D and Table S1). Remarkably, the time constant for full lipid-mixing $(19.7 \mathrm{~ms})$ and those of the fast component of content-mixing $(16.2 \mathrm{~ms})$ were almost identical when $\mathrm{Ca}^{2+}$ was added to the hemifused vesicle pairs. Most real-time traces of fluorescence intensity showed immediate jumps upon $\mathrm{Ca}^{2+}$ injection within the first few frames (Fig. 4E). These contentmixing assays clearly demonstrated that the vesicle pairs arranged through myricetinmediated SNARE AR were at a primed state.

\section{DISCUSSION}

Myricetin, that binds to SNARE complex, prevented the hemifused vesicles from proceeding to full fusion. Membrane fusion could be completed only after the SNARE-bound myricetin was removed by laccase. We hypothesize that the arrest-and-release control of membrane fusion is due to SNARE zippering regulation by binding and unbinding of myricetin to SNARE complex. We previously raised the possibility that SNARE zippering could be stopped midway by myricetin which binds near the zeroth layer (Fig. S8A). ${ }^{29}$ This would result in a half-zipped complex, in which $\mathrm{N}$-terminal halves of SNARE motifs form a fourhelix bundle, but those of C-terminal halves remain separated. Zippering stopped halfway results in the hemifusion state. ${ }^{29,38}$ The present study confirmed that myricetin inhibits inner leaflet mixing (Fig. 1A) possibly by hindering C-terminal half-zippering (Fig. S8B-D), leading to an arrest in the hemifusion state (Fig. 1C). Fluorescence resonance energy transfer (FRET) monitoring of SNARE zippering using donor (Cy3)-labeled Stx and acceptor (Cy5)labeled Vp2, which were reconstituted in $\mathrm{T}$ - and $\mathrm{V}$-vesicles, respectively, showed that the arrest was lifted and the remaining zippering process was allowed by laccase treatment (Fig. S8B-D). FRET between labeled SNARE proteins was not inhibited by myricetin when SNARE proteins were not reconstituted in membranes but were present in detergent (1\% OG) (Fig. S8E-G), indicative of complex formation throughout SNARE motifs and transmembrane domains. These contrasting results suggest that $\mathrm{C}$-terminal zippering inhibition requires the membranes, and the structure of SNARE complex captured by 
myricetin during membrane fusion is not fully zippered allowing the access of laccase to the bound myricetin. Bathochromic shift showed that myricetin bound to the SNARE complex is susceptible to laccase only when SNAREs were reconstituted in the membranes. Myricetin could be removed by laccase from the SNARE complexes that were captured during membrane fusion (Fig. 1C). But, myricetin was not removed from the complex when myricetin was co-complexed with the cytoplasmic domains of SNAREs (cdSNAREs) (Fig. $\mathrm{S} 8 \mathrm{H}$ ). Laccase probably could not gain access to the myricetin concealed inside the bundle because coiled coiling occurred throughout SNARE motifs (Fig. S8E-G). In contrast, laccase accessibility to myricetin bound to SNARE complexes on the membrane suggests that the C-terminal motif of VAMP2 is frayed consistent with our pervious results. ${ }^{29}$ Furthermore, inner leaflet mixing was not induced by $\mathrm{Ca}^{2+}$ and Syt1 (Fig. 2A) unless the zippering of the C-terminal half motif was allowed by removing myricetin from the SNARE complex (Fig. S8I). ${ }^{17-2246,47}$ Thus, it is likely that the hemifusion state was arrested by myricetin which prevented half-zippered SNARE complexes from full zippering, and the arrested zipper was rescued by laccase that removed myricetin from the half-zippered complex.

There is, however, a possibility that hemifusion state was not arrested solely because full zippering was prevented by myricetin. First, a peptide corresponding to the cytoplasmic Cterminal half of $\mathrm{Vp} 2$, whose binding energy is $>30 k_{B} T,{ }^{10,48}$ is displaced by binding of fulllength Vp2 to the t-SNARE acceptor complex. The displacement occurs both in solution and when the SNAREs are anchored onto liposomes. Thus, the idea that zippering, which is powerful enough to displace $\mathrm{C}$-terminal half of $\mathrm{Vp} 2$, can be stopped half way by a small molecule such as myricetin may not be easily acceptable. However, recent studies showed that there is an intrinsic pause near the ionic zeroth layer, which is within the potential binding site of myricetin, ${ }^{29}$ during SNARE complex formation that is stabilized by the repulsion between membranes ${ }^{10,49}$ We showed here that C-terminal zippering is inhibited by myricetin (Fig. S8). It seems that myricetin wedges into the SNARE zipper with a branch near the ionic layer. However, the structure of myricetin-bound half-zipped complex needs to be determined before the way SNARE zippering is controlled by myricetin is more clearly understood.

Second, it is arguable as to how hemifusion was achieved by only half-zippering. SNARE zippering is associated with a large release of energy that is essential for membrane fusion initiation. An elegant study assigned approximate regions responsible for the generation of docking, extended hemifusion and fusion. ${ }^{48}$ Even when assembly is allowed until the last hydrophobic layer, the $\Delta 84$ mutant does not increase hemifusion. When the 4 most Cterminal hydrophobic layers of $\mathrm{Vp} 2$ were mutated the mutants form half-zipped complex, dock membranes, but do not cause hemifusion or full-fusion. ${ }^{50,51}$ However, it was shown that partial SNARE zippering generates about $35 k_{B} T$ energy, corresponding closely to the energy needed for hemifusion. ${ }^{52}$ Furthermore, recent tweezers studies showed that the half zippering leads to a net energy release of $26 k_{B} T$ in the presence of membranes and $35 k_{B} T$ in the presence of the pre-assembled C-terminal domains. ${ }^{10,49}$ Because as few as one SNARE complex is required for bilayer fusion, ${ }^{53,54}$ and multiple SNARE complexes are available in the synaptic vesicles in the neuron, ${ }^{55,56}$ we postulate that the half-zippering of several SNARE complexes may provide energy sufficient for hemifusion. 
Third, other factors might have contributed to myricetin-mediated hemifusion state. Binding of myricetin with SNARE proteins might have lowered active SNARE concentration at the fusion site. It is known that, in viral fusion, sub-optimal conditions such as low number of activated fusogens can arrest fusion at the hemifused state. ${ }^{57}$ Interaction of myricetin with membrane might have affected membrane fusion. There is evidence of membrane binding by flavonoids, including myricetin which seems to partition at the interface between the phospholipid head groups and the acyl chains ${ }^{58,59}$ Given that hemifusion is very sensitive to lipid composition and inter-leaflet lipid asymmetry, it is possible that myricetin's effects are at least partially due to its interaction with membranes. ${ }^{57,60}$

Regardless of the exact mechanism by which myricetin results in the hemifusion intermediates, SNARE AR enables us to prepare long-lived hemifusion intermediates, even after myricetin is removed. This structural platform was used to show how $\mathrm{Ca}^{2+}$ and Syt1 differently affect fusion kinetics depending on discrete steps of membrane fusion. The primed state, which is the state enabling fast synaptic transmission at the speed of neuronal communication, was successfully recapitulated using myricetin as a reversible chemical switch (Movie 2). Fusion-competent hemifused vesicles between T- and SV-vesicles containing Syt1 could be enriched through sequential myricetin and laccase treatment (Fig. 2B). The hemifusion intermediates formed between T- and SV-vesicles was stable in the absence of either Syt1 or $\mathrm{Ca}^{2+}$ (Fig. 2C and D). This stability seems to be intrinsic to the hemifusion state. The rate constant of inner leaflet mixing of SV-vesicles (66 min, Fig. 2A, black line) was similar to those of V-vesicle (71 min, Fig. 1A), suggesting that Syt1 without $\mathrm{Ca}^{2+}$ did not stabilize the reaction in the hemifusion state. $10 \mu \mathrm{M} \mathrm{Ca}^{2+}$ triggered a fusion pore opening in $31 \%$ of all immobilized and SRB-containing vesicles with a time constant of $16.2 \mathrm{~ms}$. This result demonstrates reconstitution of an unprecedentedly rapid exocytosis triggered by a physiological concentration of $\mathrm{Ca}^{2+}$ with a rate constant that is about an order of magnitude away from the physiological phenomenon in the neuron. ${ }^{61}$ It is probable that the true rate constant is even higher than what we report here because most vesicles were observed as already fully-fused with fusion pores opened in the first frame of the videos of which temporal resolutions were $32 \mathrm{~ms}$ and $10 \mathrm{~ms}$ for lipid-mixing assay and contentmixing assay, respectively (Figs. 2E and 4E).

Lipid-mixing does not necessarily represent fusion pore opening. None of reconstitution studies to date has succeeded in showing content-mixing, which is the true indication of pore opening, triggered by physiological concentrations of $\mathrm{Ca}^{2+}$ in a millisecond timescale. Most successful content-mixing studies to date were achieved only in the presence of nonphysiological $\mathrm{Ca}^{2+}$ concentrations $(500 \mu \mathrm{M}-3 \mathrm{mM})$, and only a miniscule fraction of the vesicles responded to the $\mathrm{Ca}^{2+}$ trigger, casting doubt on whether the vesicles were really at the primed state. ${ }^{9,31}$ In contrast, vesicles that are arranged through SNARE AR exhibit the characteristics of primed vesicles in RRP in terms of speed, synchrony, and response to physiological $\mathrm{Ca}^{2+}$ concentrations. Thus, the primed state in the neuron is likely to be similar to those organized through SNARE AR, where fusion-competent and half-zipped trans-SNARE complexes dwell on the hemifused membranes.

It is controversial whether the hemifused state may correspond to the primed vesicle pool. A conical electron tomography showed that vesicles docked to the active zone are hemifused. ${ }^{62}$ 
Granules in the sea urchin egg were shown to be stably hemifused to the plasma membrane using fluorescence recovery after photobleaching. ${ }^{63}$ But, another cryoelectron tomography study argued that docked synaptic vesicles did not make membrane-to-membrane contact with the active zone. ${ }^{64}$ Electron microscopy studies using reconstituted liposomes also yielded contradicting results. Hernandez et al. found that, using a 'docking mutant', the conversion from tight docking to hemifusion or full fusion cannot be restored by Syt1. Furthermore, they showed that hemifusion accumulates and is kinetically trapped due to high-energy barrier for pore opening. ${ }^{48}$ This result contrasts to a recent study that a stable hemifusion diaphragm only resulted in slow fusion while $\mathrm{Ca}^{2+}$-triggered immediate fusion starts from point contact between membranes and completes fusion without discernible hemifusion intermediates. ${ }^{31}$ SNARE AR clearly showed that the long-lived hemifusion intermediates can immediately proceed to full fusion upon physiological $\mathrm{Ca}^{2+}$ influx.

During synchronous release, $\mathrm{Ca}^{2+}$ induces fusion of synaptic vesicles with presynaptic plasma membranes within a millisecond, achieving fast neurotransmitter release. Asynchronous release persists for tens of milliseconds to tens of seconds after an action potential invades a presynaptic bouton. ${ }^{43}$ Furthermore, in contrast to many central nervous system synapses where neurotransmitters of only a single synaptic vesicle are released in response to a presynaptic action potential, a single action potential at the neuromuscular junction triggers the exocytosis of $\sim 200$ vesicles. To achieve such a high degree of synchrony, a pool of readily releasable vesicles with the same molecular status is likely to be prepared and maintained in a manner that ensures their quick release in response to the $\mathrm{Ca}^{2+}$ signal. Consistent with previous results, ${ }^{22}$ we found that $\mathrm{Syt} 1$ and $\mathrm{Ca}^{2+}$ accelerated full lipid mixing even without a priori half-zipped trans SNARE complexes, but these reactions were asynchronous and $\sim 200$ times slower than those arranged by SNARE AR (Table S1). Furthermore, the timing of full fusion relative to docking were not synchronous among vesicles but were stochastic (Fig. 3E) while we observed highly synchronized full lipidmixing (Fig. 3B) and content-mixing (Fig. 4D) upon addition of $10 \mu \mathrm{M} \mathrm{Ca}^{2+}$ to the hemifused vesicle pairs. Thus, it is tempting to speculate that a slower form of release may be mediated through the intervention of $\mathrm{Ca}^{2+}$ into early (or all) stages of membrane fusion, including the docking step, while faster synchronous release is mediated by $\mathrm{Ca}^{2+}$-Syt1 inducing hemifused vesicles to progress to full fusion. It may be possible that most docked vesicles are not hemifused. If there is a slow conversion of docked vesicles to the hemifused state, which then slowly undergo inner lipid mixing, this could correspond to spontaneous fusion. In contrast, if $\mathrm{Ca}^{2+}$ increases while a few vesicles are in the hemifused state, fast fusion would ensue from the hemifused state (corresponding to synchronous release). Fusion from the docked (not hemifused) state could correspond to slower, asynchronous release.

In this study, we could clearly show how $\mathrm{Ca}^{2+}$ and Syt1 differently affect fusion kinetics depending on discrete fusion steps of membrane fusion. This was possible because we could arrange the hemifusion intermediates. Because synaptic proteins such as Syt1, complexin 1 and SM proteins were shown to have multiple functions in neuroexocytosis, $2,3,13,14,27,65,66$ SNARE AR can provide a structural platform to separately test the effect of these proteins on each step of fusion process leading to pore opening. 


\section{Supplementary Material}

Refer to Web version on PubMed Central for supplementary material.

\section{Acknowledgments}

This work was supported by the Basic Science Research Program through the National Research Foundation of Korea Grant funded by the Ministry of Science, ICT \& Future Planning (2009-0083540) and by a grant from the Korea Healthcare Technology R\&D Project, Ministry of Health \& Welfare, Republic of Korea (Grant No.: HN10C00300000 and HN14C01010000) to D.-H.K., KIST institutional program (2E26320) to Y. Y., and the U.S. National Science Foundation grant (PHY 1430124) to T. H. T.H. is an investigator of the Howard Hughes Medical Institute.

\section{REFERENCES}

1. Weber T, Zemelman BV, McNew JA, Westermann B, Gmachl M, Parlati F, Sollner TH, Rothman JE. Cell. 1998; 92:759. [PubMed: 9529252]

2. Sudhof TC, Rizo J. Cold Spring Harbor Perspect. Biol. 2011; 3:a005637.

3. Jahn R, Fasshauer D. Nature. 2012; 490:201. [PubMed: 23060190]

4. Sutton RB, Fasshauer D, Jahn R, Brunger AT. Nature. 1998; 395:347. [PubMed: 9759724]

5. Sudhof TC, Rothman JE. Science. 2009; 323:474. [PubMed: 19164740]

6. Poirier MA, Xiao WZ, Macosko JC, Chan C, Shin YK, Bennett MK. Nat. Struct. Biol. 1998; 5:765. [PubMed: 9731768]

7. Xu T, Rammner B, Margittai M, Artalejo AR, Neher E, Jahn R. Cell. 1999; 99:713. [PubMed: 10619425]

8. Pobbati AV, Stein A, Fasshauer D. Science. 2006; 313:673. [PubMed: 16888141]

9. Kyoung M, Srivastava A, Zhang Y, Diao J, Vrljic M, Grob P, Nogales E, Chu S, Brunger AT. Proc. Natl. Acad. Sci. U.S.A. 2011; 108:304.

10. Gao Y, Zorman S, Gundersen G, Xi Z, Ma L, Sirinakis G, Rothman JE, Zhang Y. Science. 2012; 337:1340. [PubMed: 22903523]

11. Min D, Kim K, Hyeon C, Cho YH, Shin YK, Yoon TY. Nat. commun. 2013; 4:1705. [PubMed: 23591872]

12. Katz B, Miledi R. Proc. R. Soc. London Ser. B. 1965; 161:483. [PubMed: 14278409]

13. Rizo J, Rosenmund C. Nat. Struct. Mol. Biol. 2008; 15:665. [PubMed: 18618940]

14. Chicka MC, Hui E, Liu H, Chapman ER. Nature Struct. Mol. Biol. 2008; 15:827. [PubMed: 18622390]

15. Maximov A, Tang J, Yang X, Pang ZP, Sudhof TC. Science. 2009; 323:516. [PubMed: 19164751]

16. Yang X, Kaeser-Woo YJ, Pang ZP, Xu W, Sudhof TC. Neuron. 2010; 68:907. [PubMed: 21145004]

17. Arac D, Chen X, Khant HA, Ubach J, Ludtke SJ, Kikkawa M, Johnson AE, Chiu W, Sudhof TC, Rizo J. Nat. Struct. Mol. Biol. 2006; 13:209. [PubMed: 16491093]

18. Martens S, Kozlov MM, McMahon HT. Science. 2007; 316:1205. [PubMed: 17478680]

19. Stein A, Radhakrishnan A, Riedel D, Fasshauer D, Jahn R. Nat. Struct. Mol. Biol. 2007; 14:904. [PubMed: 17891149]

20. Xue M, Ma C, Craig TK, Rosenmund C, Rizo J. Nat. Struct. Mol. Biol. 2008; 15:1160. [PubMed: 18953334]

21. Hui E, Johnson CP, Yao J, Dunning FM, Chapman ER. Cell. 2009; 138:709. [PubMed: 19703397]

22. Lee HK, Yang Y, Su Z, Hyeon C, Lee TS, Lee HW, Kweon DH, Shin YK, Yoon TY. Science. 2010; 328:760. [PubMed: 20448186]

23. van den Bogaart G, Thutupalli S, Risselada JH, Meyenberg K, Holt M, Riedel D, Diederichsen U, Herminghaus S, Grubmuller H, Jahn R. Nat. Struct. Mol. Biol. 2011; 18:805. [PubMed: 21642968]

24. Bykhovskaia M, Jagota A, Gonzalez A, Vasin A, Littleton JT. Biophys. J. 2013; 105:679. [PubMed: 23931316] 
25. Zimmerberg J, Akimov SA, Frolov V. Nat. Struct. Mol. Biol. 2006; 13:301. [PubMed: 16715046]

26. Brunger AT, Weninger K, Bowen M, Chu S. Annu. Rev. Biochem. 2009; 78:903. [PubMed: 19489736]

27. Ma C, Su L, Seven AB, Xu Y, Rizo J. Science. 2013; 339:421. [PubMed: 23258414]

28. Kiessling V, Ahmed S, Domanska MK, Holt MG, Jahn R, Tamm LK. Biophys. J. 2013; 104:1950. [PubMed: 23663838]

29. Yang Y, Shin JY, Oh JM, Jung CH, Hwang Y, Kim S, Kim JS, Yoon KJ, Ryu JY, Shin J, Hwang JS, Yoon TY, Shin YK, Kweon DH. Proc. Natl. Acad. U.S.A. 2010; 107:22145.

30. Yoon TY, Okumus B, Zhang F, Shin YK, Ha T. Proc. Natl. Acad. U.S.A. 2006; 103:19731.

31. Diao J, Grob P, Cipriano DJ, Kyoung M, Zhang Y, Shah S, Nguyen A, Padolina M, Srivastava A, Vrljic M, Shah A, Nogales E, Chu S, Brunger AT. eLife. 2012; 1:e00109. [PubMed: 23240085]

32. McIntyre JC, Sleight RG. Biochemistry. 1991; 30:11819. [PubMed: 1751498]

33. Lu XB, Zhang F, McNew JA, Shin YK. J. Biol. Chem. 2005; 280:30538. [PubMed: 15980065]

34. Samaj J, Baluska F, Voigt B, Schlicht M, Volkmann D, Menzel D. Plant Physiol. 2004; 135:1150. [PubMed: 15266049]

35. Roy R, Hohng S, Ha T. Nat. Methods. 2008; 5:507. [PubMed: 18511918]

36. Chung SH, Kennedy RA. J. Neurosci. Methods. 1991; 40:71. [PubMed: 1795554]

37. Haran G. Chem. Phys. 2004; 307:137.

38. Yang Y, Heo P, Kong B, Park JB, Jung YH, Shin J, Jeong C, Kweon DH. Biochem. Biophys. Res. Commun. 2015; 465:864. [PubMed: 26319432]

39. Jiménez M, García-Carmona F. J. Sci. Food Agric. 1999; 79:1993.

40. Zick M, Wickner WT. eLife. 2014:3.

41. Zhou Q, Lai Y, Bacaj T, Zhao M, Lyubimov AY, Uervirojnangkoorn M, Zeldin OB, Brewster AS, Sauter NK, Cohen AE, Soltis SM, Alonso-Mori R, Chollet M, Lemke HT, Pfuetzner RA, Choi UB, Weis WI, Diao J, Sudhof TC, Brunger AT. Nature. 2015; 525:62. [PubMed: 26280336]

42. Bhalla A, Chicka MC, Tucker WC, Chapman ER. Nat. Struct. Mol. Biol. 2006; 13:323. [PubMed: 16565726]

43. Kaeser PS, Regehr WG. Annu. Rev. Physiol. 2014; 76:333. [PubMed: 24274737]

44. Diao J, Ishitsuka Y, Lee H, Joo C, Su Z, Syed S, Shin YK, Yoon TY, Ha T. Nat. protocols. 2012; 7:921. [PubMed: 22582418]

45. Kyoung M, Zhang Y, Diao J, Chu S, Brunger AT. Nat. protocols. 2013; 8:1. [PubMed: 23222454]

46. Laage R, Rohde J, Brosig B, Langosch D. J. Biol. Chem. 2000; 275:17481. [PubMed: 10764817]

47. Stein A, Weber G, Wahl MC, Jahn R. Nature. 2009; 460:525. [PubMed: 19571812]

48. Hernandez JM, Stein A, Behrmann E, Riedel D, Cypionka A, Farsi Z, Walla PJ, Raunser S, Jahn R. Science. 2012; 336:1581. [PubMed: 22653732]

49. Zorman S, Rebane AA, Ma L, Yang GC, Molski MA, Coleman J, Pincet F, Rothman JE, Zhang YL. eLife. 2014:3.

50. Krishnakumar SS, Kummel D, Jones SJ, Radoff DT, Reinisch KM, Rothman JE. Biophys. J. 2013; 105:2507. [PubMed: 24314081]

51. Krishnakumar SS, Radoff DT, Kummel D, Giraudo CG, Li F, Khandan L, Baguley SW, Coleman J, Reinisch KM, Pincet F, Rothman JE. Nat. Struct. Mol. Biol. 2011; 18:934. [PubMed: 21785412]

52. Li F, Pincet F, Perez E, Eng WS, Melia TJ, Rothman JE, Tareste D. Nat. Struct. Mol. Biol. 2007; 14:890. [PubMed: 17906638]

53. van den Bogaart G, Holt MG, Bunt G, Riedel D, Wouters FS, Jahn R. Nat. Struct. Mol. Biol. 2010; 17:358. [PubMed: 20139985]

54. Shi L, Shen QT, Kiel A, Wang J, Wang HW, Melia TJ, Rothman JE, Pincet F. Science. 2012; 335:1355. [PubMed: 22422984]

55. Lang T, Bruns D, Wenzel D, Riedel D, Holroyd P, Thiele C, Jahn R. EMBO J. 2001; 20:2202. [PubMed: 11331586]

56. Takamori S, Holt M, Stenius K, Lemke EA, Gronborg M, Riedel D, Urlaub H, Schenck S, Brugger B, Ringler P, Muller SA, Rammner B, Grater F, Hub JS, De Groot BL, Mieskes G, Moriyama Y, 
Klingauf J, Grubmuller H, Heuser J, Wieland F, Jahn R. Cell. 2006; 127:831. [PubMed: 17110340]

57. Chernomordik LV, Kozlov MM. Cell. 2005; 123:375. [PubMed: 16269330]

58. Scheidt HA, Pampel A, Nissler L, Gebhardt R, Huster D. Biochim. Biophys. Acta, Biomembr. 2004; 1663:97.

59. Selvaraj S, Krishnaswamy S, Devashya V, Sethuraman S, Krishnan UM. Prog Lipid Res. 2015; 58:1. [PubMed: 25479162]

60. Warner JM, O'Shaughnessy B. Biophys. J. 2012; 103:689. [PubMed: 22947930]

61. Bruns D, Jahn R. Nature. 1995; 377:62. [PubMed: 7659162]

62. Zampighi GA, Zampighi LM, Fain N, Lanzavecchia S, Simon SA, Wright EM. Biophys. J. 2006; 91:2910. [PubMed: 16877508]

63. Wong JL, Koppel DE, Cowan AE, Wessel GM. Dev. Cell. 2007; 12:653. [PubMed: 17420001]

64. Fernandez-Busnadiego R, Zuber B, Maurer UE, Cyrklaff M, Baumeister W, Lucic V. J. Cell Biol. 2010; 188:145. [PubMed: 20065095]

65. Li F, Pincet F, Perez E, Giraudo CG, Tareste D, Rothman JE. Nat. Struct. Mol. Biol. 2011; 18:941. [PubMed: 21785413]

66. Dhara M, Yarzagaray A, Schwarz Y, Dutta S, Grabner C, Moghadam PK, Bost A, Schirra C, Rettig J, Reim K, Brose N, Mohrmann R, Bruns D. J. Cell Biol. 2014; 204:1123. [PubMed: 24687280] 
A

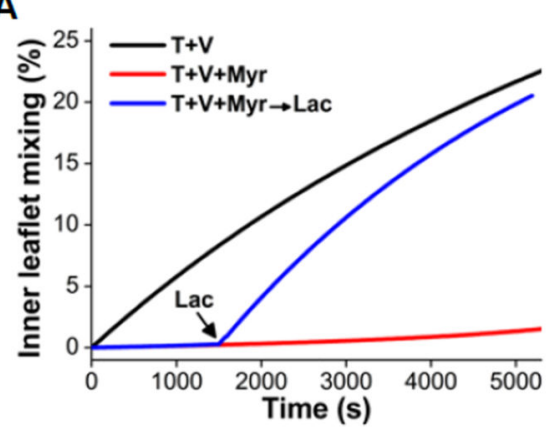

D

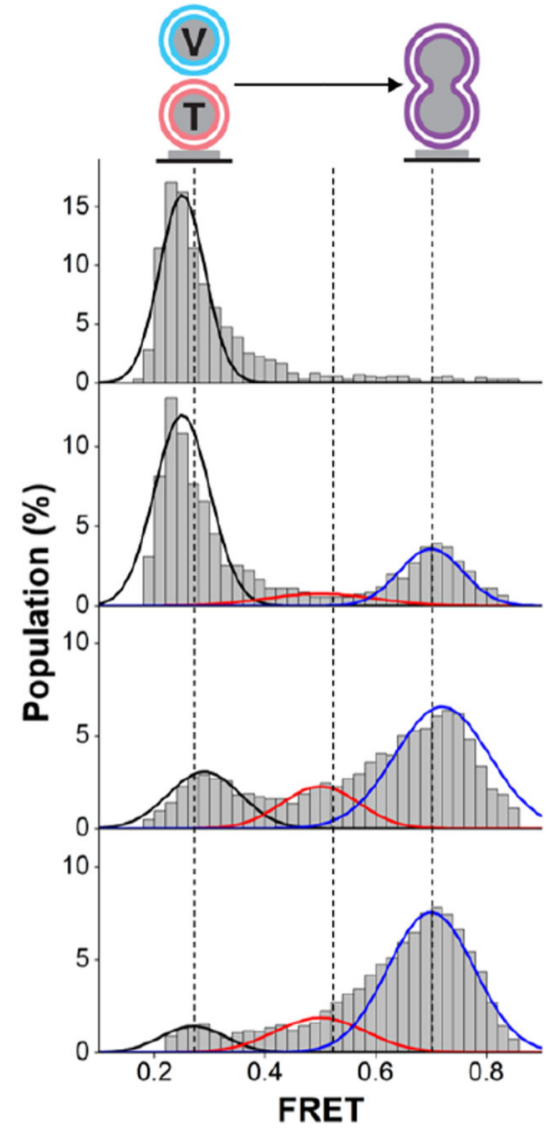

B

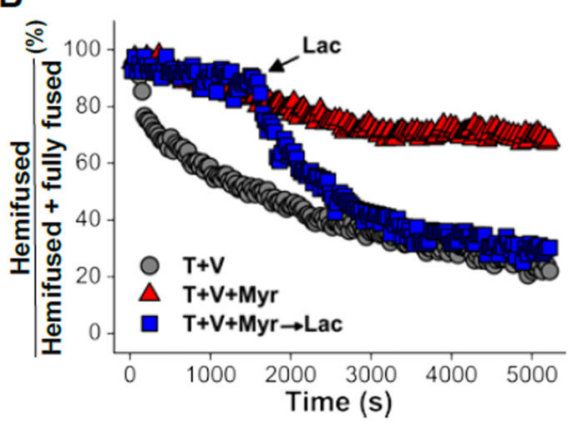

Arrest

E

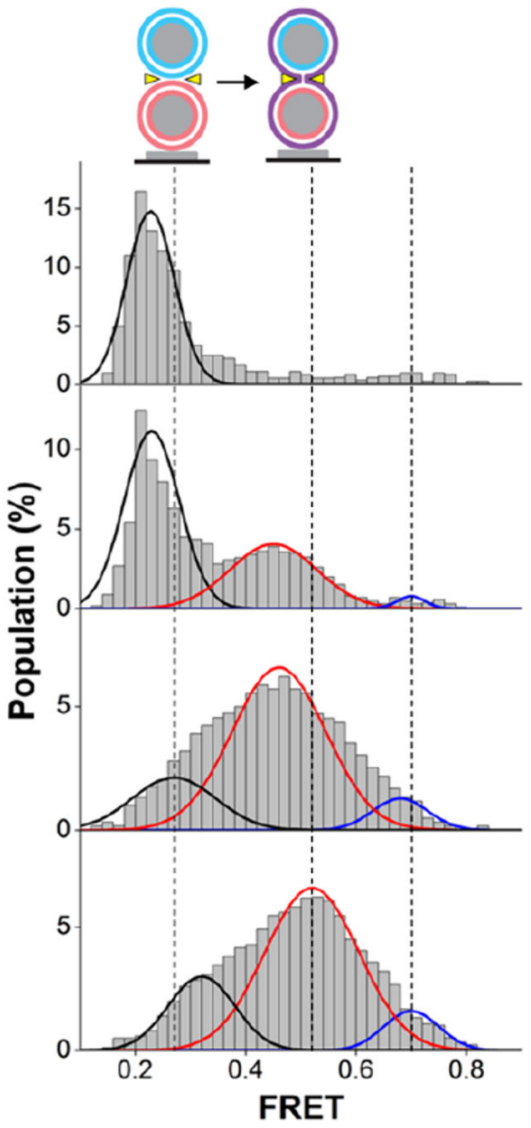

C

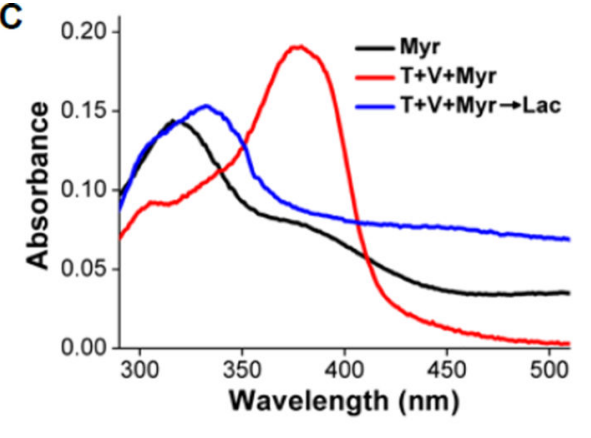

$\underline{\text { Release }}$

F $\quad \mathrm{T}+\mathrm{V}+\mathrm{Myr} \rightarrow \mathrm{Lac}$

Figure 1. Myricetin-mediated arrest-and-release control of SNARE-driven membrane fusion (SNARE AR)

(A) Inner leaflet mixing assays performed in the presence (red) or absence (black) of myricetin. During lipid mixing, laccase (Lac, $10 \mathrm{U}$ ) was added to the reaction mixture to remove the myricetin bound to SNARE complex at the time designated by an arrow (blue). (B) The percentage of hemifusion was calculated based on the lipid mixing assays of Fig. 1A. (C) Bathochromic shift of myricetin after binding to the SNARE complex of T- and Vvesicles and after removing it from the complex using laccase. (D-F) Single-vesicle lipid mixing assay of SNARE AR. Each histogram was deconvoluted to 3 populations; docking (black line), hemifusion (red line) and full fusion (blue line). (D) Vesicle populations 
produced after incubating DiD-labeled T- and DiI-labeled V-vesicles at $37^{\circ} \mathrm{C}$. (E) Arrest of the hemifusion state by myricetin (100 nM, yellow triangle). (F) Hemifused vesicles immobilized on the surface could be relieved from the arrest by treatment with laccase, leading to full fusion. 
A

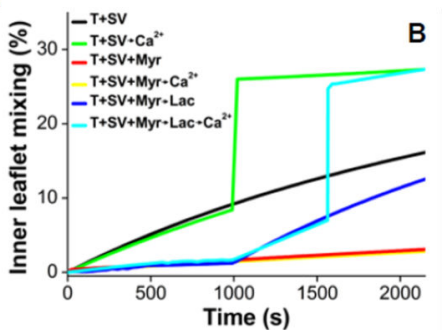

Scheme A
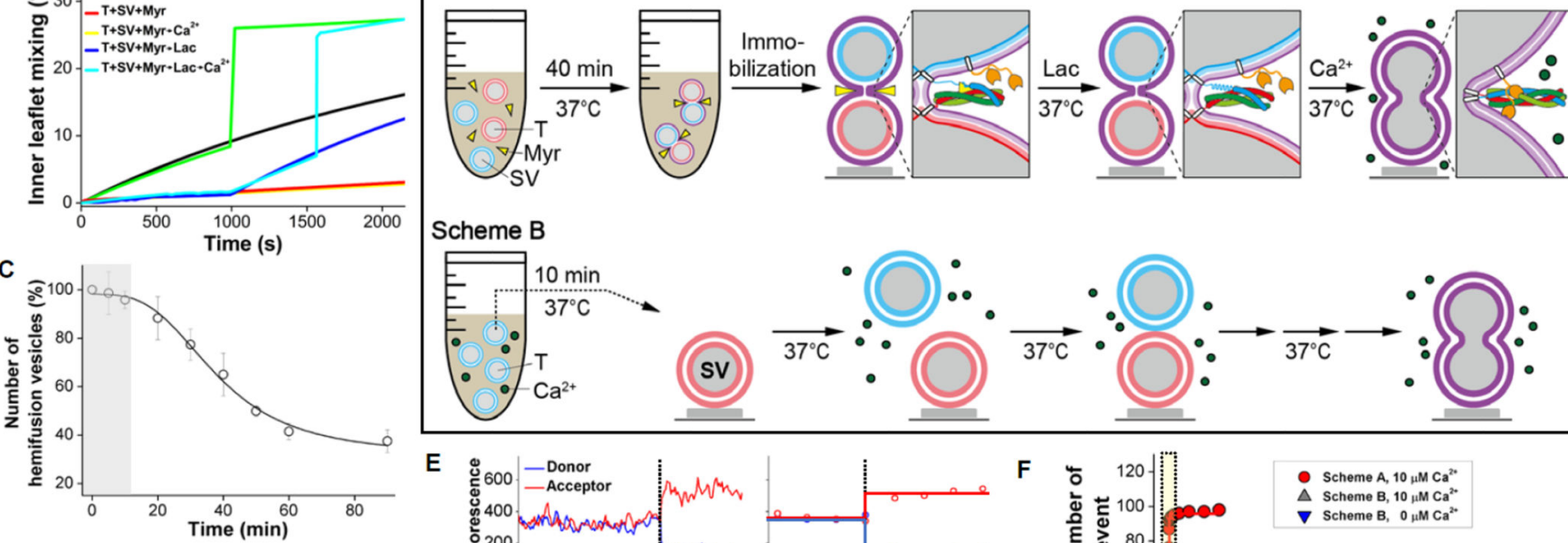

D

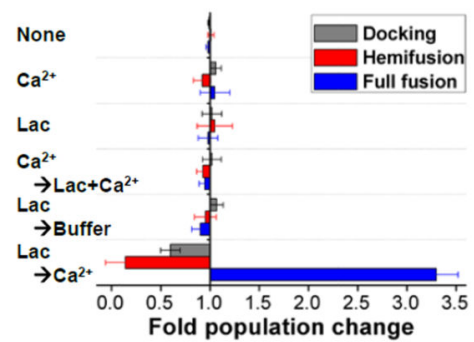

Scheme B

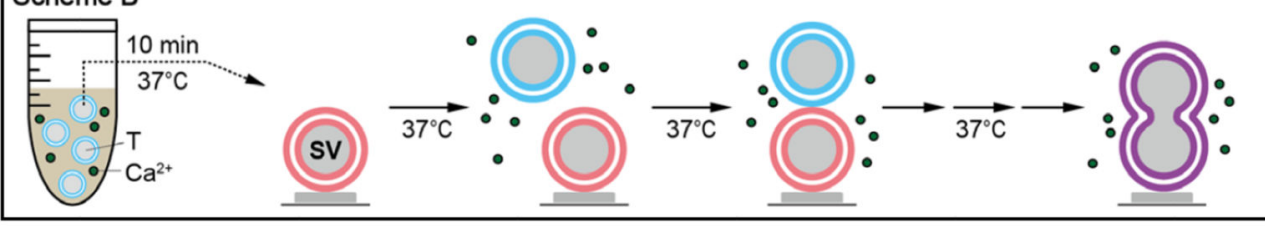

E
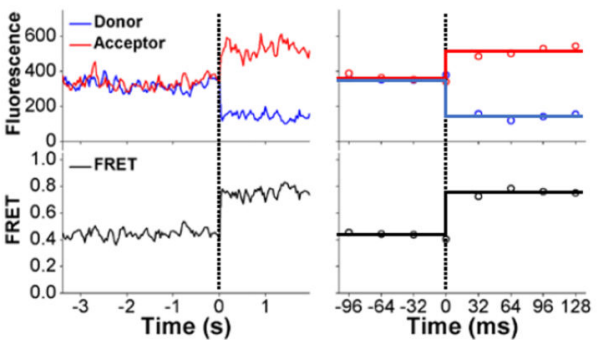

G

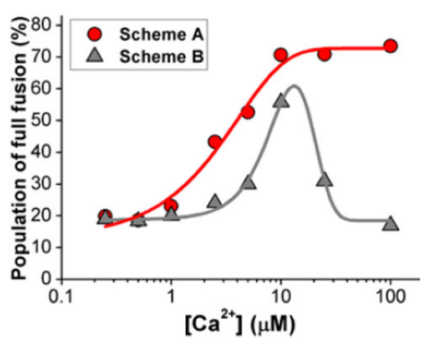

F
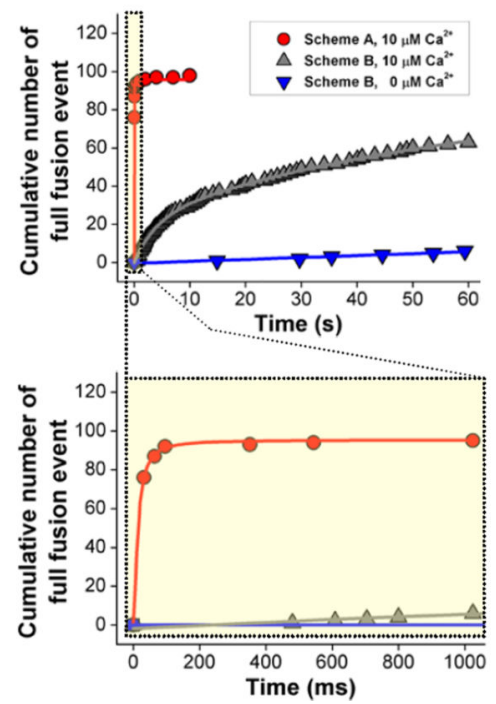

Figure 2. Dissection of fusion step-specific effects of Syt1 and $\mathrm{Ca}^{2+}$ on full lipid mixing

(A) Arrest-and-release control of ensemble inner leaflet lipid mixing between T- and SVvesicles. Lipid mixing between T- and SV-vesicles was performed in the presence (red) or absence (black) of myricetin. When $500 \mu \mathrm{M}$ calcium was added to the reaction mixture of Tand SV-vesicles, fast lipid mixing induced by calcium (green) was observed. However, in the presence of $5 \mu \mathrm{M}$ myricetin, $\mathrm{Ca}^{2+}$ did not induce fast lipid mixing (yellow). When myricetin was removed by the addition of laccase, lipid mixing resumed (blue) and fast membrane fusion was triggered by $\mathrm{Ca}^{2+}$ (cyan). Arrows indicate the time of injection of laccase and/or $\mathrm{Ca}^{2+}$. (B) Scheme A, a scheme to test the effect of $\mathrm{Ca}^{2+}$ and Syt1 on hemifusion-to-full fusion transition through SNARE AR. Hemifused vesicles containing Syt1 were prepared by incubating T- and SV-vesicles with myricetin. After the hemifused vesicles were immobilized on glass slides and free myricetin was washed out, laccase treatment was carried out at $37^{\circ} \mathrm{C}$ for $10 \mathrm{~min}$ to make the vesicles fusion-competent. After washing out the laccase, $\mathrm{Ca}^{2+}$ was injected into the chamber at $37^{\circ} \mathrm{C}$. Lipids composition for T-vesicles and

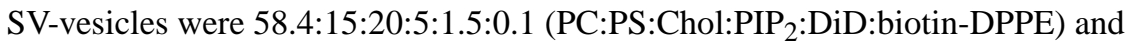
63.5:15:20:1.5 (PC:PS:Chol:DiI), respectively. Scheme B, a scheme to test acceleration of docking-to-full fusion transition by $\mathrm{Ca}^{2+}$ and Syt1. T-vesicles containing the indicated concentration of $\mathrm{Ca}^{2+}$ at $37{ }^{\circ} \mathrm{C}$ were directly injected onto the surface of immobilized SVvesicles. Lipids composition for T-vesicles and SV-vesicles were 33.5:15:20:25:5:1.5 
(PC:PS:Chol:DOPE:PIP 2 :DiI) and 50.4:3:20:25:1.5:0.1 (PC:PS:Chol:DOPE:DiD:biotinDPPE), respectively. Aggregated vesicles were excluded from the analysis after identifying single-vesicle pairs for all experiments (Fig. S4). (C) Decay kinetics of the hemifused vesicles prepared through SNARE AR. T- and SV-vesicles were incubated together with myricetin. After the vesicles were immobilized on the glass surface, laccase was added. The number of hemifused vesicles was counted during incubation of laccase at $37^{\circ} \mathrm{C}$ up to 90 $\mathrm{min}$. There was $\sim 10 \mathrm{~min}$ lag period (shaded) before exponential decay because myricetin needs to be removed by laccase for hemifusion to proceed to full fusion. (D) Population changes of lipid mixing intermediates before and after various treatments. After $1 \mathrm{~min}$ incubation following each treatment, the number of each population (docked, hemifused, or fully fused vesicles) in percentage was divided by those before the treatment. Thus, a value 1 designates no change in the composition of the population. Experiments were replicated 3 times. (E) Representative real-time trace of a single-vesicle fusion event prepared through SNARE AR. $10 \mu \mathrm{M} \mathrm{Ca}^{2+}$ was injected at time $0 \mathrm{~ms}$. Fluorescence intensity of donor (blue), acceptor (red) and corresponding FRET (black) are shown in the time range of s (left) and ms (right). (F) Cumulative number of full fusion events as a function of time, where $t$ is the time elapsed after $\mathrm{Ca}^{2+}$ injection. The area shaded in yellow in $(\mathrm{F})$ is magnified to better contrast the fusion-step specific effect of $\mathrm{Ca}^{2+}$ on full lipid mixing. (G) Fusion stepdependent effect of $\mathrm{Ca}^{2+}$ on a full fusion event. After injecting the indicated concentrations of $\mathrm{Ca}^{2+}$ following scheme $\mathrm{A}$ or $\mathrm{B}$, fractions of full fusion were obtained after $1 \mathrm{~min}$. 
A

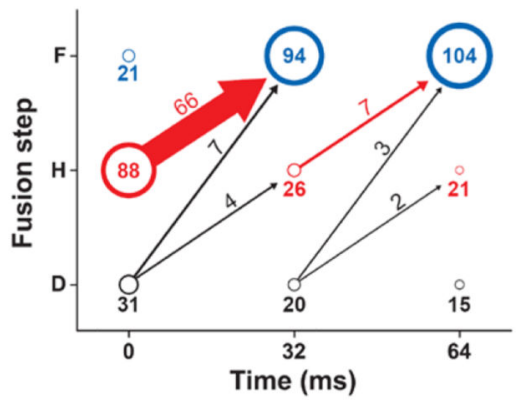

D

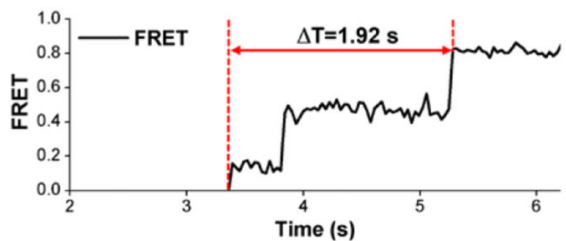

B

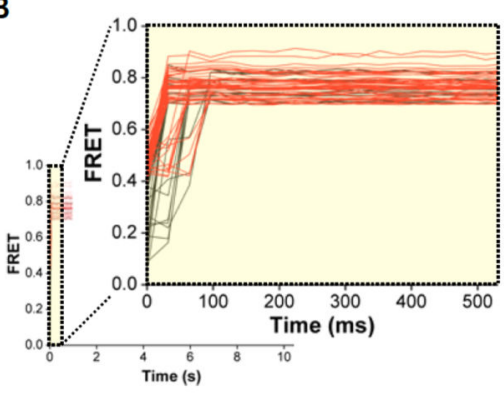

E

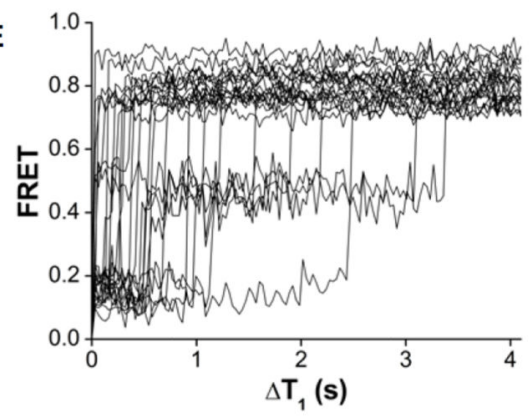

C

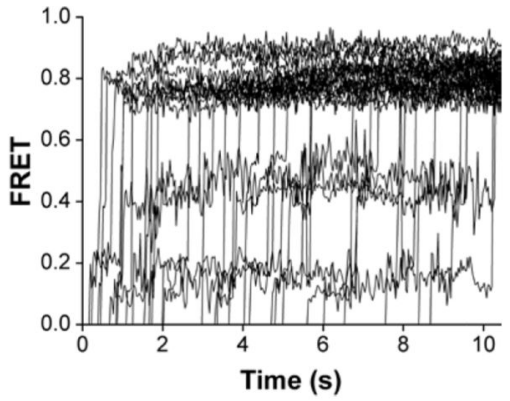

F

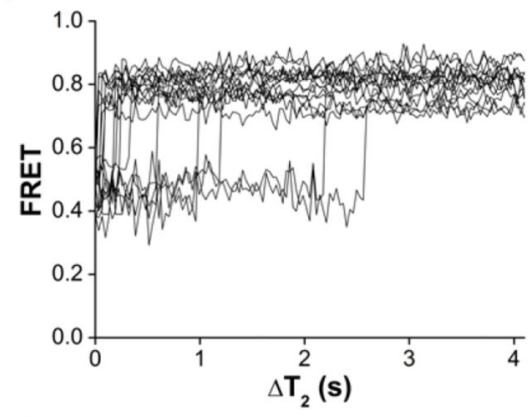

G

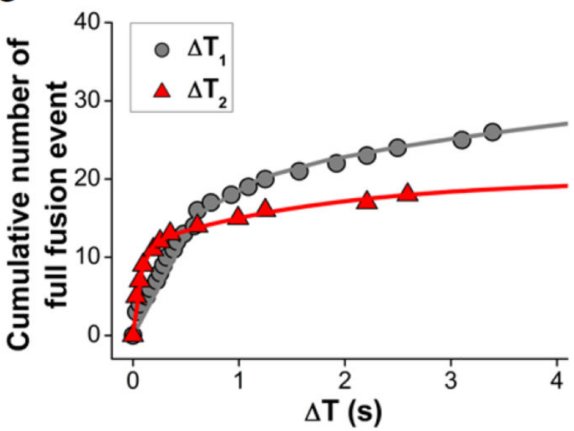

Figure 3. Hemifusion intermediate is essential for $\mathrm{Ca}^{2+}$-triggered immediate and synchronous fusion

(A) Time-dependent changes in the number of fusion intermediates after $\mathrm{Ca}^{2+}$ influx following scheme A. Numbers are the averages of vesicle numbers from three independent experiments: D, docked; $\mathrm{H}$, hemifused; F, fully fused vesicles. Arrows indicate the origin and destination of a membrane fusion event. (B) Overlay of all FRET changes occurring for $10 \mathrm{~s}$ after $\mathrm{Ca}^{2+}$ injection following scheme A. Inset, the area shaded in yellow were magnified to show FRET traces during the period 0 500 ms. (C) Overlay of all FRET traces occurring for $10 \mathrm{~s}$ after $\mathrm{Ca}^{2+}$ injection following scheme B. (D) Definition of time gap between docking and full fusion $\left(\Delta \mathrm{T}_{1}\right)$, and between hemifusion and full fusion $\left(\Delta \mathrm{T}_{2}\right) .(\mathrm{E})$ Overlay of all FRET changes occurring after the emergence of docking signal following scheme B. (F) Overlay of all FRET changes occurring after the emergence of hemifusion signal following scheme B. (E) Cumulative number of full fusion events as a function of time, where $\Delta \mathrm{T}_{1}$ is the time gap between docking and full fusion, and $\Delta \mathrm{T}_{2}$ is the time gap between hemifusion and full fusion. 
A

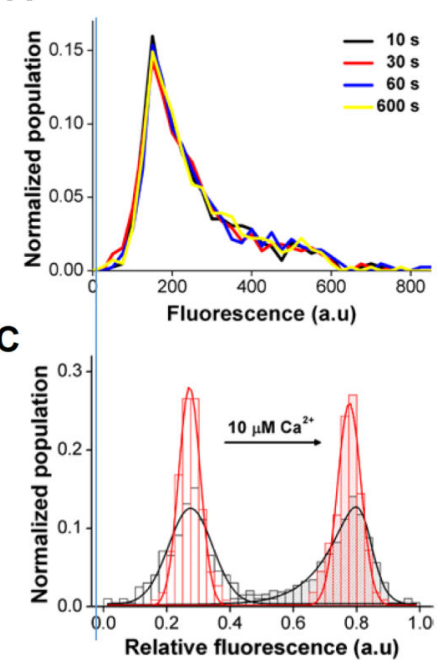

B

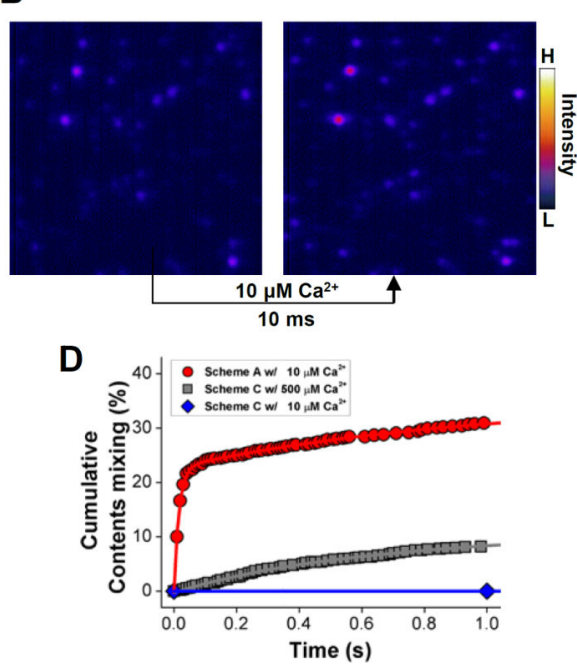

\section{$\mathbf{E}$}

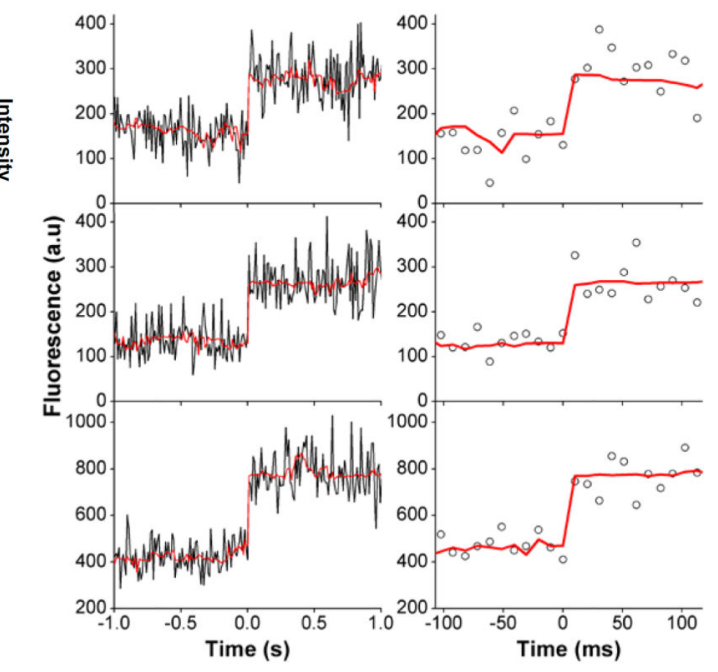

Figure 4. Single-vesicle content-mixing assay of vesicles primed through SNARE AR (A) Fluorescence intensity distributions of vesicles arranged through SNARE AR. After performing the SNARE AR procedure using T- and SRB-encapsulated SV-vesicles, the vesicles were immobilized to the imaging surface through biotinylated lipids on T-vesicles. Lack of change in fluorescence intensity for $10 \mathrm{~min}$ indicates that there was no measurable SRB leakage or un-triggered fusion without $\mathrm{Ca}^{2+}$. (B) Snapshot images of a single-vesicle content mixing assay before and after $\mathrm{Ca}^{2+}$ injection. (C) Change in fluorescence intensity distribution by $\mathrm{Ca}^{2+}$-triggered content mixing. The relative fluorescence intensity histogram, recorded from eight independent experiments, showed that $\mathrm{Ca}^{2+}$ triggered the increase of fluorescence intensity through content mixing. Black and red bars were derived from the black and red lines of $(\mathrm{E})$, respectively (see the Methods for calculating relative fluorescence and its fitting). (D) Cumulative \% of content mixing as a function of time. (E)

Representative real-time traces of SRB fluorescence intensity during single-vesicle content mixing assay. $10 \mu \mathrm{M} \mathrm{Ca}^{2+}$ was injected at time $0 \mathrm{~ms}$. Data fitting (red lines) was performed as described in the Materials and Methods. 